\section{Prenatal ultrasonography of craniofacial abnormalities}

\author{
Annisa Shui Lam Mak, Kwok Yin Leung \\ Department of Obstetrics and Gynaecology, Queen Elizabeth Hospital, Hong Kong SAR, \\ China
}

Craniofacial abnormalities are common. It is important to examine the fetal face and skull during prenatal ultrasound examinations because abnormalities of these structures may indicate the presence of other, more subtle anomalies, syndromes, chromosomal abnormalities, or even rarer conditions, such as infections or metabolic disorders. The prenatal diagnosis of craniofacial abnormalities remains difficult, especially in the first trimester. A systematic approach to the fetal skull and face can increase the detection rate. When an abnormality is found, it is important to perform a detailed scan to determine its severity and search for additional abnormalities. The use of 3-/4-dimensional ultrasound may be useful in the assessment of cleft palate and craniosynostosis. Fetal magnetic resonance imaging can facilitate the evaluation of the palate, micrognathia, cranial sutures, brain, and other fetal structures. Invasive prenatal diagnostic techniques are indicated to exclude chromosomal abnormalities. Molecular analysis for some syndromes is feasible if the family history is suggestive.

Keywords: Craniofacial; Prenatal; Ultrasound; Three-dimensional ultrasonography;

Fetal structural abnormalities

\section{Introduction}

Craniofacial abnormalities are common. In particular, the prevalence of facial clefts and craniosynostosis is around $0.15 \%$ and $0.05 \%$, respectively [1-4]. Antenatal ultrasonography is an accurate and reliable tool for detecting these malformations [5]. It is important to examine the fetal face and skull during prenatal ultrasound examinations because abnormalities of these structures may indicate the presence of other, more subtle anomalies, syndromes, chromosomal abnormalities, or even rarer conditions, such as infections or metabolic disorders. Whenever a craniofacial abnormality is found, it is important to perform a detailed scan to screen for additional anomalies. Additional use of 3-/4-dimensional (3D/4D) ultrasonography or fetal magnetic resonance imaging (MRI) may facilitate searching for or precisely delineating certain anomalies $[6,7]$. Further investigations, including invasive prenatal diagnostic techniques, may be indicated for chromosomal studies or molecular testing.

The detection rate of craniofacial abnormalities varies depending on the type of abnormality, its severity, gestational age, associated anomalies, and the techniques and technology of the ultrasound examinations. The prenatal diagnosis of some abnormalities, such as craniosynostosis, remains

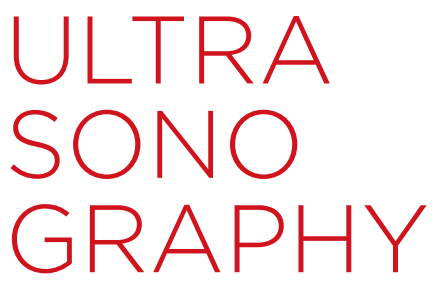

\section{REVIEW ARTICLE}

https://doi.org/10.14366/usg.18031 pISSN: 2288-5919 • elSSN: 2288-5943

Ultrasonography 2019;38:13-24

Received: May 29, 2018

Revised: June 30, 2018

Accepted: July 3, 2018

Correspondence to:

Kwok Yin Leung, MBBS, MD, FRCOG,

Cert HKCOG (MFM), Department of

Obstetrics and Gynaecology, Queen

Elizabeth Hospital, Gascoigne Road,

Kowloon, Hong Kong SAR, China

Tel. +852-3506 6398

Fax. $+852-23845834$

E-mail: leungky1@ha.org.hk

This is an Open Access article distributed under the terms of the Creative Commons Attribution NonCommercial License (http://creativecommons.org/ licenses/by-nc/3.0/) which permits unrestricted noncommercial use, distribution, and reproduction in any medium, provided the original work is properly cited.

Copyright (C) 2019 Korean Society of Ultrasound in Medicine (KSUM)

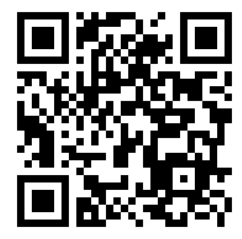

How to cite this article:

Mak ASL, Leung KY. Prenatal ultrasonography of craniofacial abnormalities. Ultrasonography. 2019 Jan;38(1):13-24. 
low [8]. Nonetheless, over-diagnosis should be avoided because most fetuses with isolated brachycephaly or dolichocephaly have normal outcomes. Various professional societies, including International Society of Ultrasound in Obstetrics and Gynecology (ISUOG), American Institute of Ultrasound in Medicine, and the Asia and Oceania Federation of Obstetrics \& Gynecology have issued guidelines on the examination of the face and skull in the secondtrimester anomaly scan [9-11]. In recent years, examining the fetal craniofacial structures in the first-trimester sonography examination has been recommended $[10,12]$. The main purpose of this review is to provide up-to-date information on prenatal sonography of craniofacial abnormalities, with the goal of increasing diagnostic accuracy.

\section{Skull}

The size, shape, integrity, and bone density of the skull can be assessed when the head size is measured and when the brain

Table 1. Abnormal ultrasonographic features of the skull and associated abnormalities

\begin{tabular}{cll}
\hline Feature & \multicolumn{1}{c}{ Abnormal feature } & \multicolumn{1}{c}{ Abnormality } \\
\hline Size & Small & Microcephaly \\
& Large & Macrocephaly \\
Shape & Not oval, like a lemon, & Spina bifida, trisomy 18, or \\
strawberry, or cloverleaf & skeletal dysplasia \\
Integrity & $\begin{array}{l}\text { Defect in the skull bone with } \\
\text { protrusion of brain tissue }\end{array}$ & Encephalocele \\
Density & $\begin{array}{l}\text { Absence of echogenicity, } \\
\text { skull easily compressed }\end{array}$ & $\begin{array}{l}\text { Poor mineralization, such as } \\
\text { osteogenesis imperfecta or } \\
\text { hypophosphatasia }\end{array}$ \\
\hline
\end{tabular}

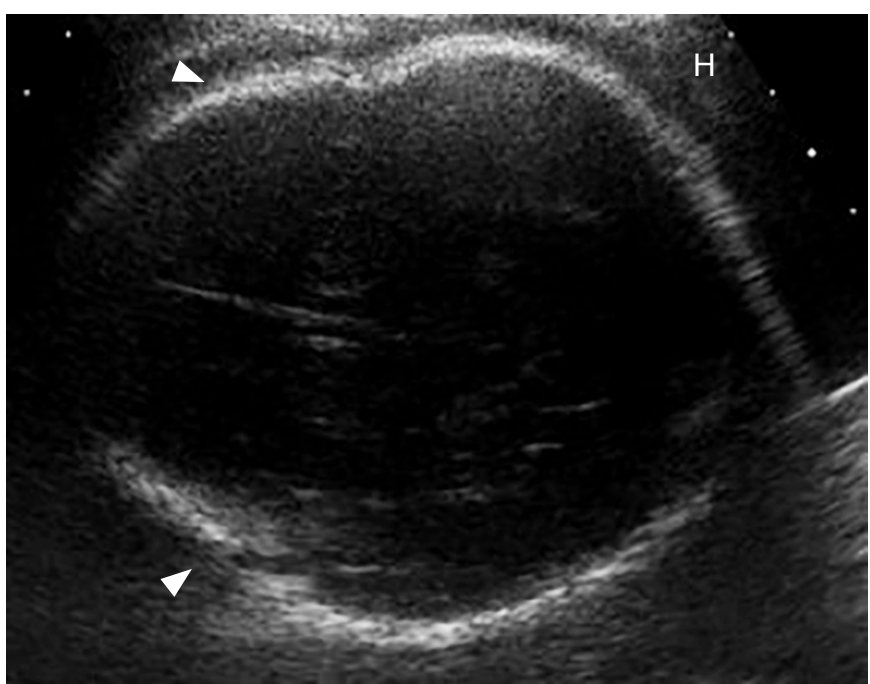

Fig. 1. A second-trimester fetus with trigonocephaly. Axial view of the fetal head $(\mathrm{H})$ shows a triangular shaped forehead (arrowheads). structures are examined [10]. The skull has an oval shape and continuous echogenic structure interrupted only by narrow echolucent sutures. Abnormal features (Figs. 1-3) and associated abnormalities are shown in Table 1.

The prenatal ultrasound diagnosis of craniosynostosis is difficult. It can be made directly when there is a loss of hypoechogenicity in a segment of the normal skull sutures, together with enlargement of other orthogonal sutures [13]. Indirect signs, including an abnormal cephalic index (CI), cranial shape (Table 2), and/or face morphology

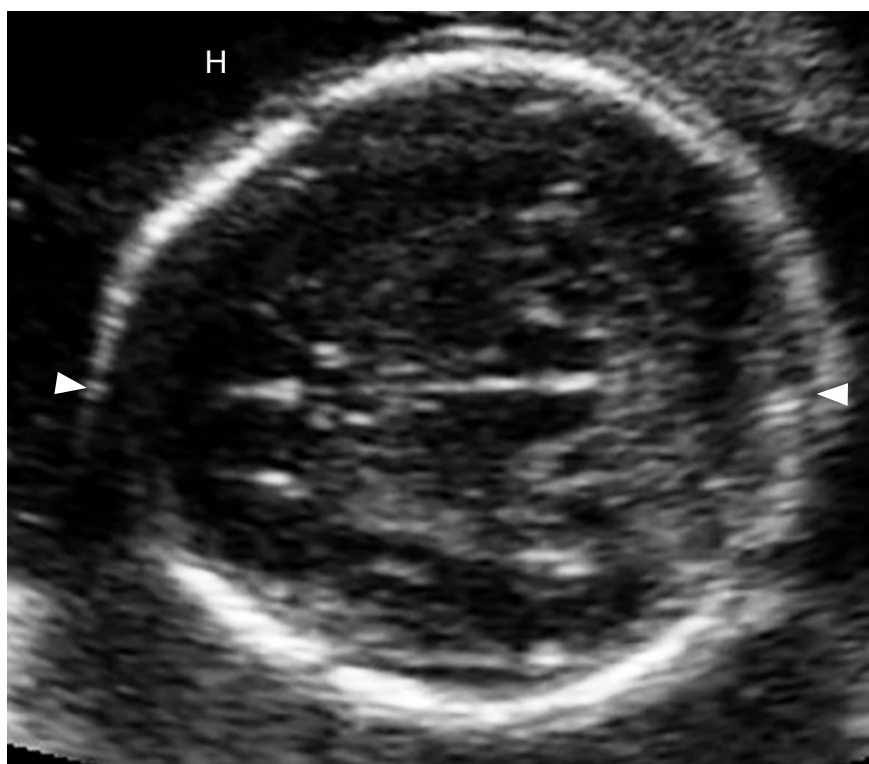

Fig. 2. A second-trimester fetus with brachycephaly. Axial view of the fetal head $(\mathrm{H})$ shows the shape of the skull is shorter than typical (arrowheads).

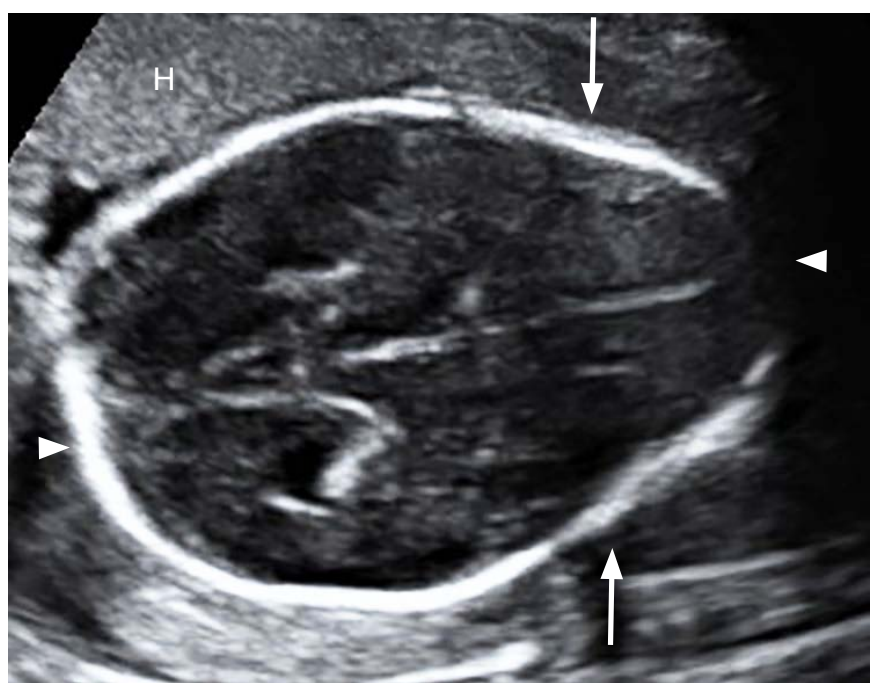

Fig. 3. A second-trimester fetus with scaphocephaly. Axial view of the fetal head $(\mathrm{H})$ shows a long (arrowheads) and narrow head (arrows). 
Table 2. Different types of craniosynostosis and associated abnormalities

\begin{tabular}{lll}
\hline \multicolumn{1}{c}{ Abnormal shape } & Suture synostosis & Associated abnormalities \\
\hline $\begin{array}{l}\text { Scaphocephaly/ } \\
\text { Dolichocephaly (long) }\end{array}$ & Sagittal & \\
$\begin{array}{l}\text { Brachycephaly (short, } \\
\text { broad) }\end{array}$ & Bilateral coronal & Down syndrome \\
& & Pfeiffer syndrome \\
$\begin{array}{l}\text { Plagiocephaly } \\
\text { (ipsilateral forehead or } \\
\text { occipital flattening) }\end{array}$ & Unilateral coronal or & \\
$\begin{array}{l}\text { Trigonocephaly } \\
\text { (forward pointing) }\end{array}$ & Metopic & \\
$\begin{array}{l}\text { Cloverleaf (trilobate) } \\
\text { Sagittal, coronal, and }\end{array}$ & $\begin{array}{l}\text { Thanatophoric dysplasia, } \\
\text { lambdoid }\end{array}$ & $\begin{array}{l}\text { Apert syndrome, Crouzon } \\
\text { syndrome }\end{array}$ \\
& & Carpenter syndrome \\
& & \\
$\begin{array}{l}\text { Oxycephaly (pointed } \\
\text { or conical) }\end{array}$ & $\begin{array}{l}\text { Sagittal and } \\
\text { lambdoid }\end{array}$ & - \\
\hline
\end{tabular}

such as hypotelorism or hypertelorism, may precede closure of the sutures by 4 to 16 weeks [8]. Cls below $70 \%$ or above $85 \%$ indicate dolichocephaly and brachycephaly, respectively [14]. Although the $\mathrm{Cl}$ is lower in dolichocephalic fetuses, it may not be appropriate for second-trimester screening, and it may not detect trigonocephaly [15]. Further investigations including 3D ultrasonography or MRI may help to diagnose closure of the sutures [16].

Measuring head size is important, as measurements of head circumference more than 3 standard deviations below or 2 standard deviations above the mean head circumference expected based on gestational age are a clue for the possible diagnosis of microcephaly or macrocephaly, respectively. However, using these reference values may lead to the over-diagnosis of microcephaly [17]. There are difficulties and pitfalls in diagnosing microcephaly based on head circumference alone. Other supporting signs include a sloping forehead, flat occiput, or intracranial content that is abnormal or not visible.

Table 3. Systematic examination of various facial structures and their abnormalities

\begin{tabular}{|c|c|c|c|}
\hline Views & Structure & Abnormal features & Abnormalities \\
\hline \multirow[t]{4}{*}{ Coronal } & Lip & Loss of integrity & Facial cleft \\
\hline & Mouth & Small or continuous, open & Microstomia or syndromes \\
\hline & Nose & Flat or one nostril & Hypoplasia, single-nostril syndromes \\
\hline & Palpebral fissure & Upward or downward slant & \\
\hline \multirow[t]{7}{*}{ Transverse } & Orbits & Small, absence, abnormal interocular diameter & Microphthalmia/anophthalmia, hypotelorism/hypertelorism \\
\hline & & Medial cyst & Dacryocystocele \\
\hline & Lens & Echogenic & Cataract \\
\hline & Tooth buds & Cleft, abnormal number & Cleft palate, oligodontia/anodontia \\
\hline & Mandible & Small & Micrognathia \\
\hline & Uvula & Absent or double 'equals sign' & Cleft uvula \\
\hline & Ears & Abnormal size, shape, location, or rotation & Abnormal ear \\
\hline \multirow[t]{12}{*}{ Sagittal } & Forehead & Bossing & Skeletal dysplasia \\
\hline & & Sloping & Microcephaly \\
\hline & & Abnormal mass & Proboscis \\
\hline & Nose & Flat & Syndromes \\
\hline & & Absence or short nasal bone & Aneuploidies \\
\hline & Maxilla & Premaxillary protrusion & Bilateral facial cleft \\
\hline & Soft palate & No soft palate or 'equals sign' & Cleft soft palate, uvula \\
\hline & Philtrum & Long or short & Syndromes \\
\hline & Mandible & Small chin & Micrognathia \\
\hline & Symmetry & Asymmetry of face & Facial asymmetry \\
\hline & Tongue & Large, protrusion, mass backward displacement & Macroglossia, tumor glossoptosis \\
\hline & Ears & Abnormal size, shape, mass, or location or rotation & Small, dysplastic, absent, large, polyp, low-set \\
\hline
\end{tabular}




\section{Face}

It is preferable to systematically examine the fetal face in three planes to assess various facial structures because doing so facilitates the detection of abnormalities in those structures (Table 3) [18]. According to the ISUOG guidelines, the minimum evaluation of the fetal face includes the presence of both orbits, evaluation of the nose/nostrils, presence of the mouth, and preferably an evaluation of the facial profile and lip [9].

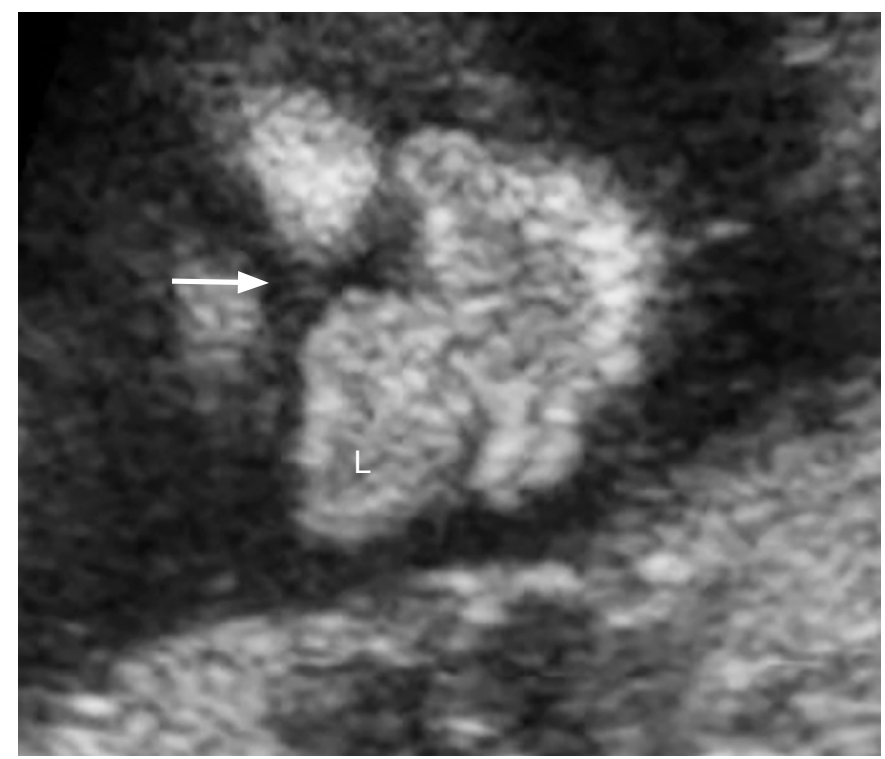

Fig. 4. A second-trimester fetus with unilateral cleft lip. Coronal view of the fetal face shows a loss of integrity (arrow) of the upper $\operatorname{lip}(\mathrm{L})$.

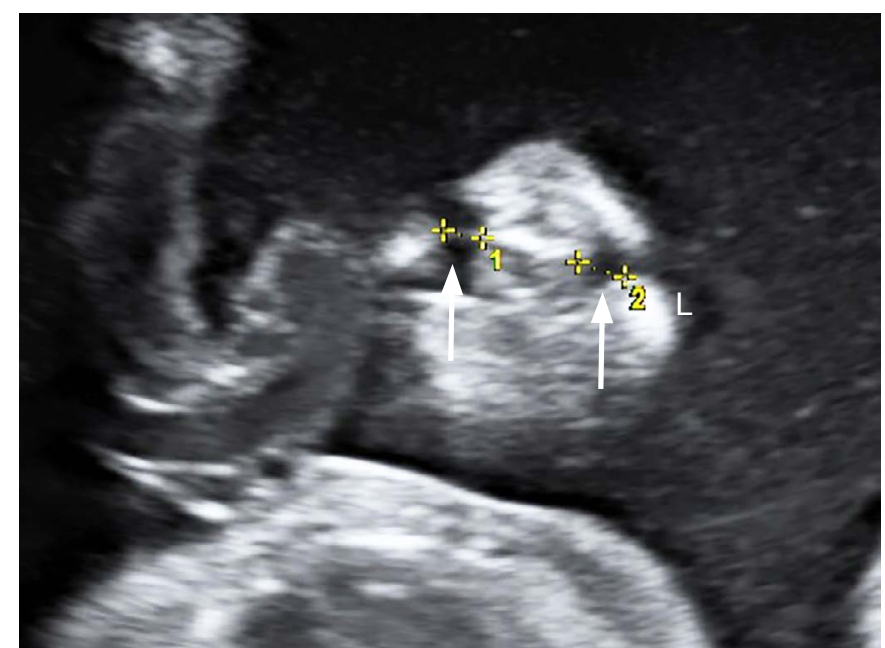

Fig. 5. A second-trimester fetus with bilateral cleft lip. Coronal view of the fetal face shows a loss of integrity (arrows) of the upper lip (L) on both sides (1 and 2).
Cleft is diagnosed when there is a loss of integrity of the lip on one or both sides on the coronal view (Figs. 4, 5). Bilateral cleft lip is suggested by the presence of a premaxillary protuberance on the sagittal view (Fig. 6). It is difficult to diagnose incomplete cleft lip (Fig. 7), cleft

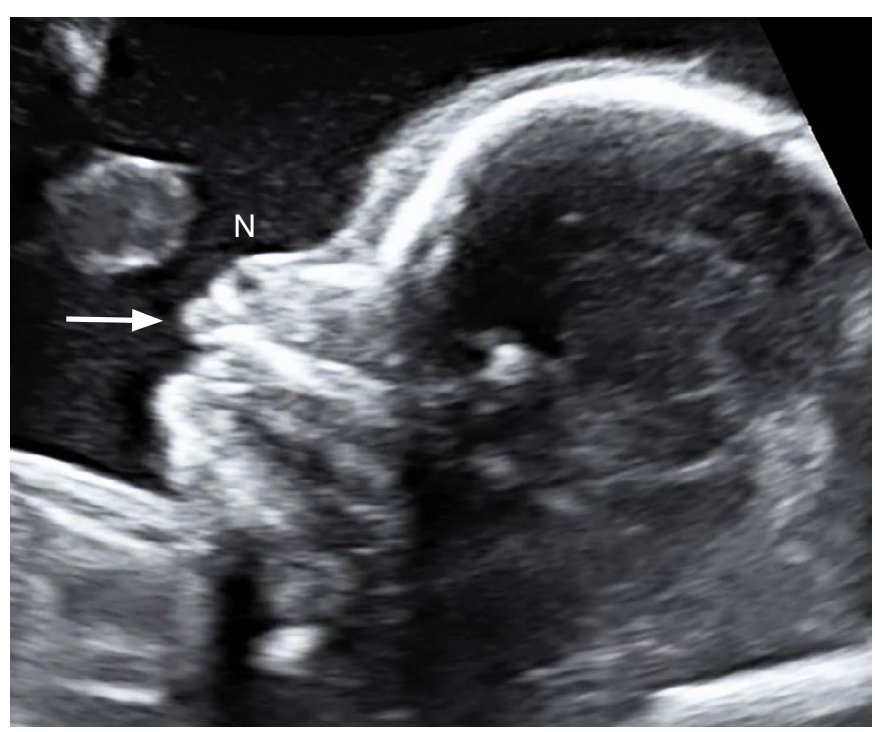

Fig. 6. A second-trimester fetus with a premaxillary protuberance. Sagittal view of the fetal face shows a soft tissue mass (arrow) protruding forward below the nose (N).

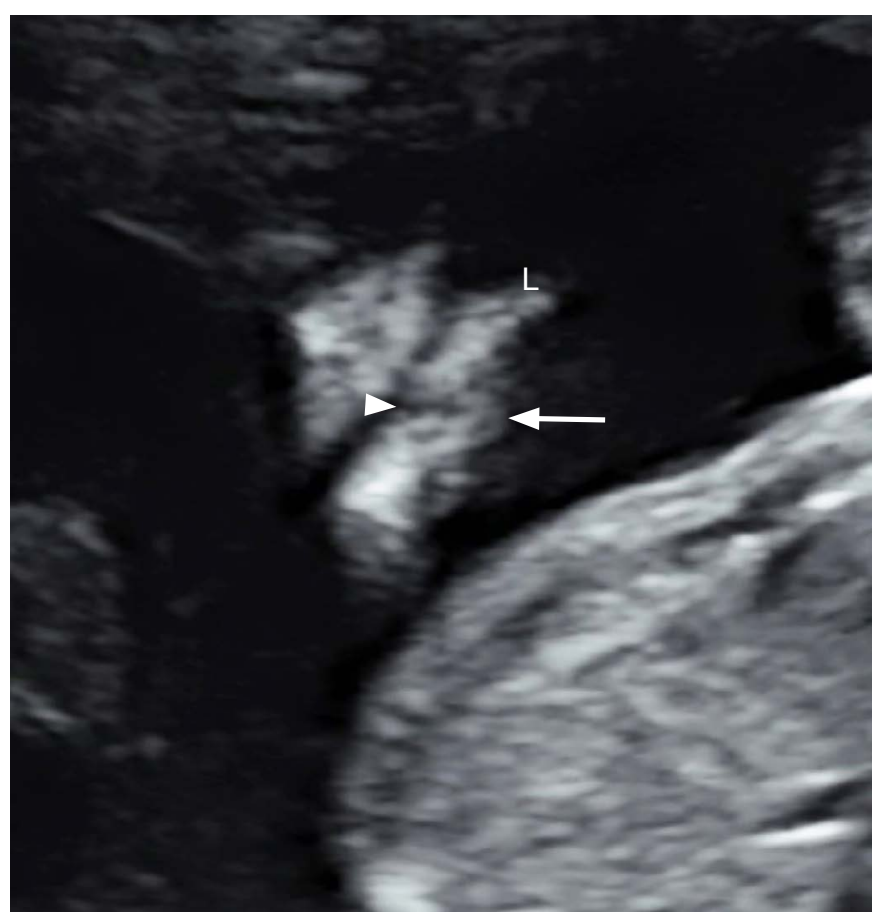

Fig. 7. A second-trimester fetus with partial unilateral cleft lip. Coronal view of the fetal face shows partial loss of integrity (arrowhead and arrow) of the upper lip (L). 


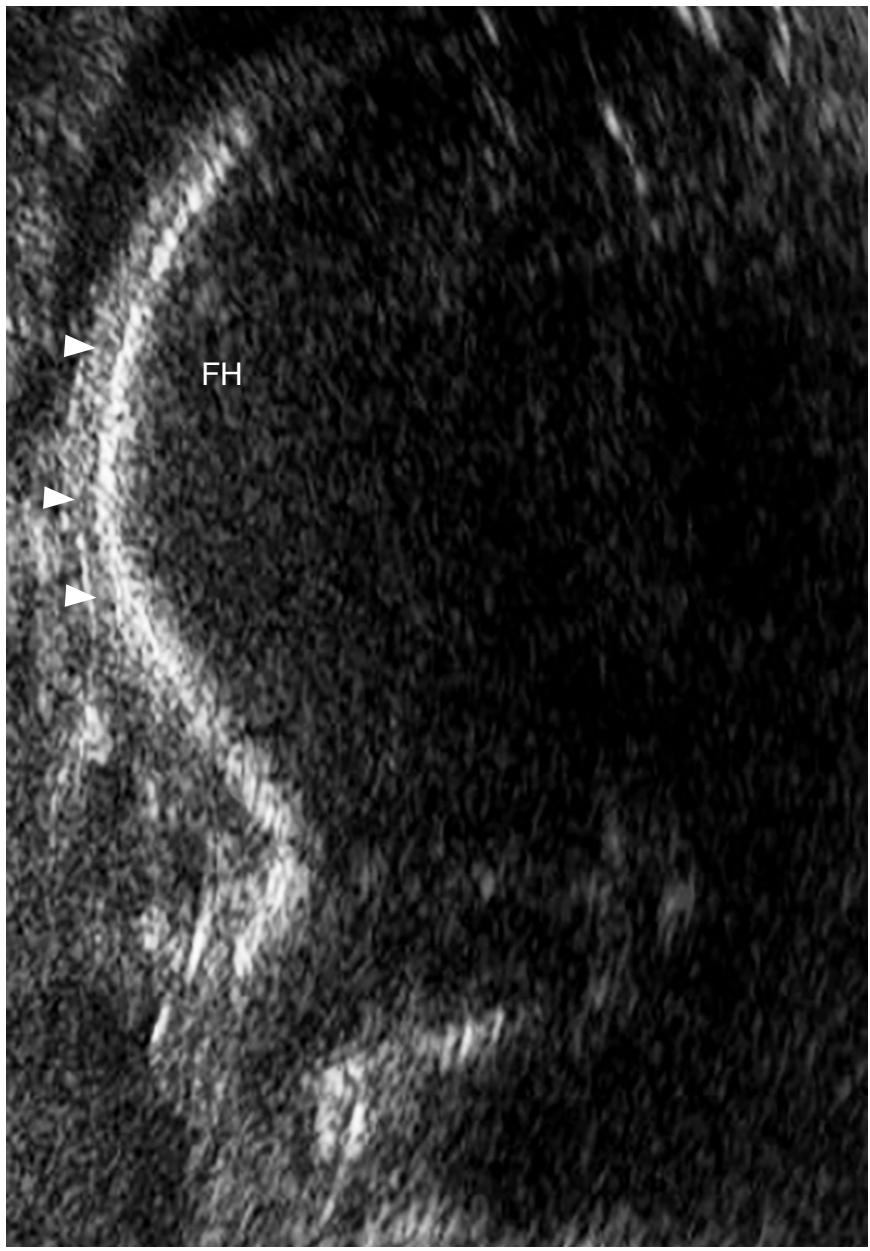

Fig. 8. A second-trimester fetus with bossing forehead. Midsagittal view of the fetal face shows a forward protuberance (arrowheads) of the forehead (FH).

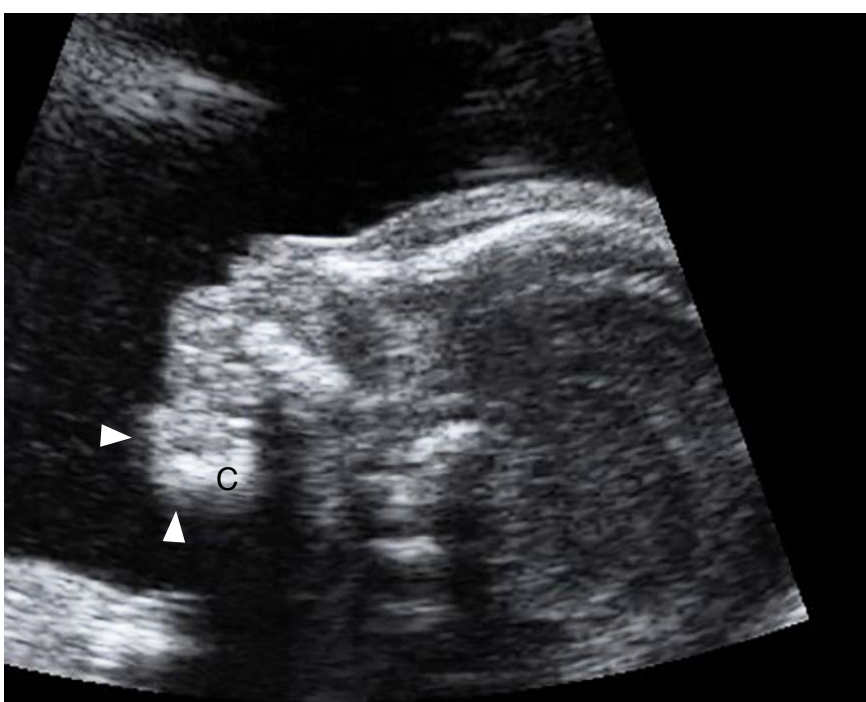

Fig. 9. A second-trimester fetus with micrognathia. Mid-sagittal view of the fetal face shows a small and receding (arrowheads) chin (C). palate alone, or cleft soft palate [19]. Indirect sonographic signs of cleft palate may include a small or absent stomach bubble and polyhydramnios. Using color flow, the flow of amniotic fluid can be seen, normally coming through the nostrils during respiratory activity or abnormally through the palate when it has a cleft. Absence of the "equals sign" is a sign of cleft palate [20]. A normal philtrum should not be mistaken for a median cleft lip.

The facial profile can be assessed on the mid-sagittal view. In particular, frontal bossing (Fig. 8), micrognathia (Fig. 9), or a flat nose (Fig. 10) can be detected. On the lateral side of the head, ear abnormalities (Fig. 11) can be assessed. Both eyes and their abnormalities can be assessed on the axial view (Figs. 12-14).

Micrognathia refers to a small mandible, while retrognathia is a posteriorly displaced mandible. Using the inferior facial angle and the ratio of the mandible width to the maxilla width may help detect these two abnormalities [21]. When there is a significant family history or a suspected anomaly, measurements of fetal structures, such as nasal bone length, ear length, maxillary length, and ocular and interocular diameters can be performed.

\section{Three-Dimensional or Four-Dimensional Ultrasound}

The use of 3D ultrasound, including surface rendering, multiplanar, and multi-slice views, allows a precise evaluation of various craniofacial structures and their abnormalities, including cleft palate

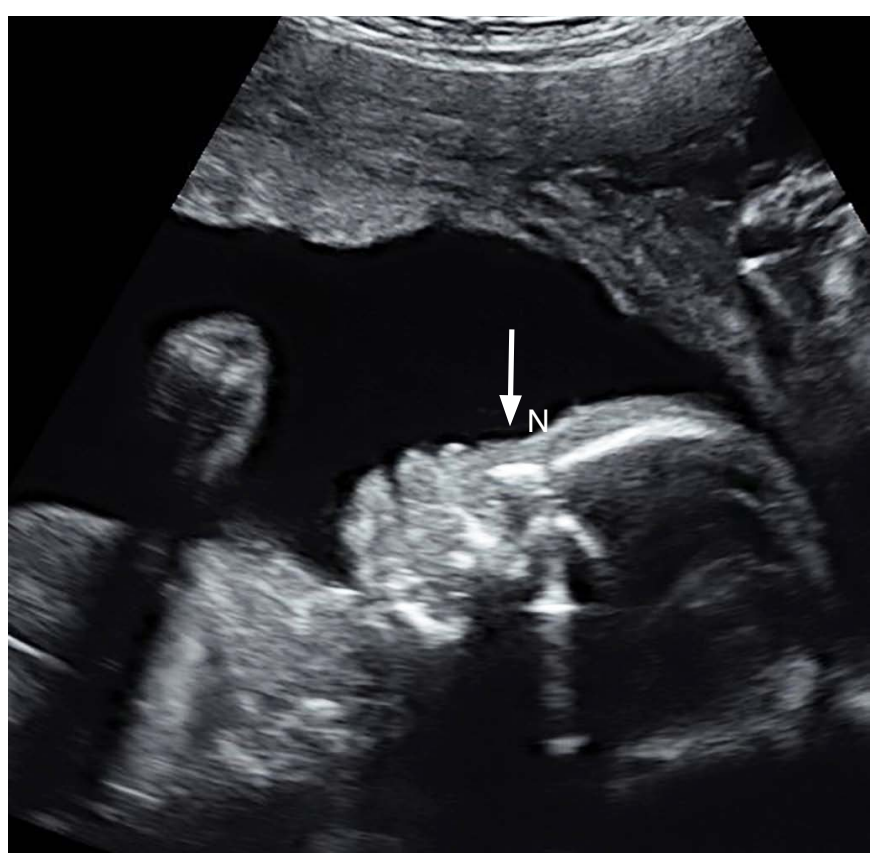

Fig. 10. A second-trimester fetus with a flat nose. Mid-sagittal view of the fetal face shows a flat (arrow) nose (N). 


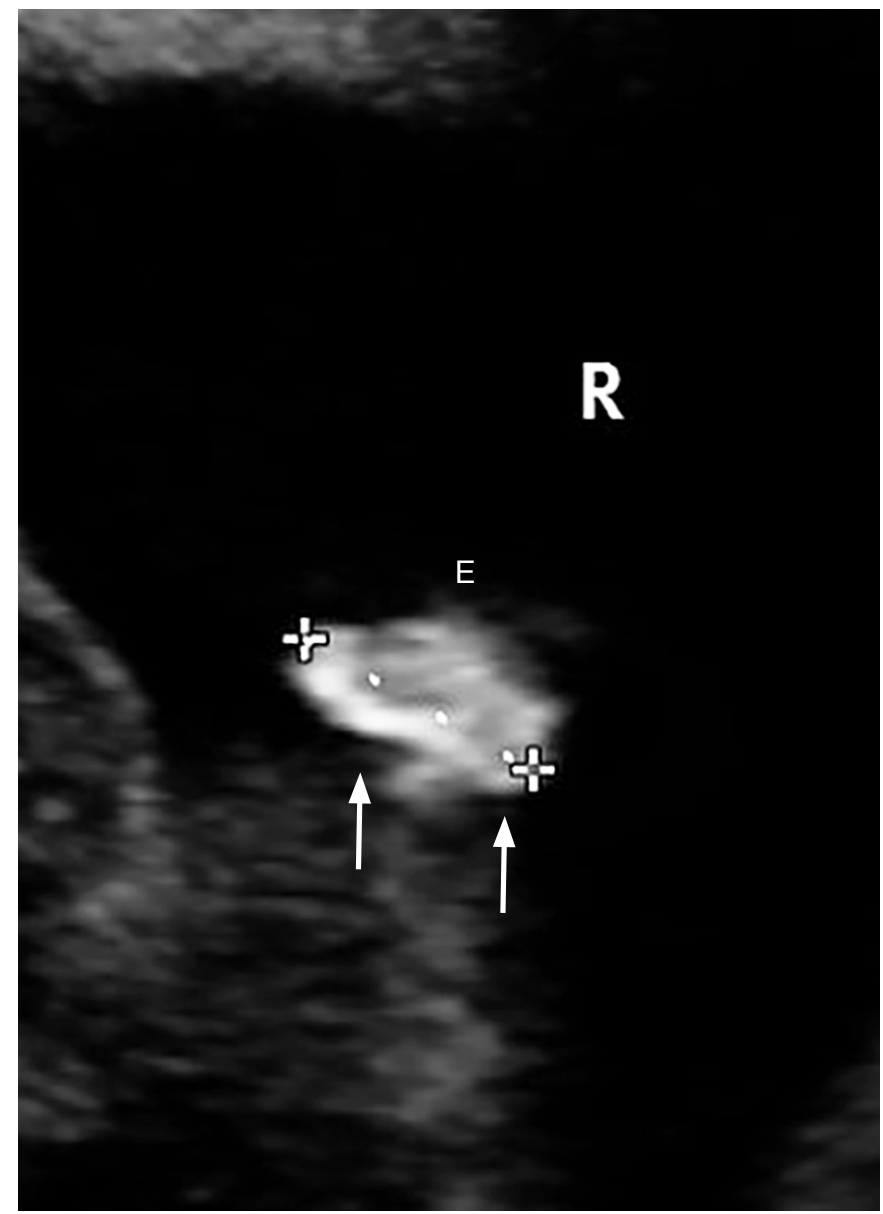

Fig. 11. A second-trimester fetus with an abnormal ear. Lateral sagittal view of the fetal face shows a small (arrows) right $(R)$ ear $(E)$ with loss of normal architecture.

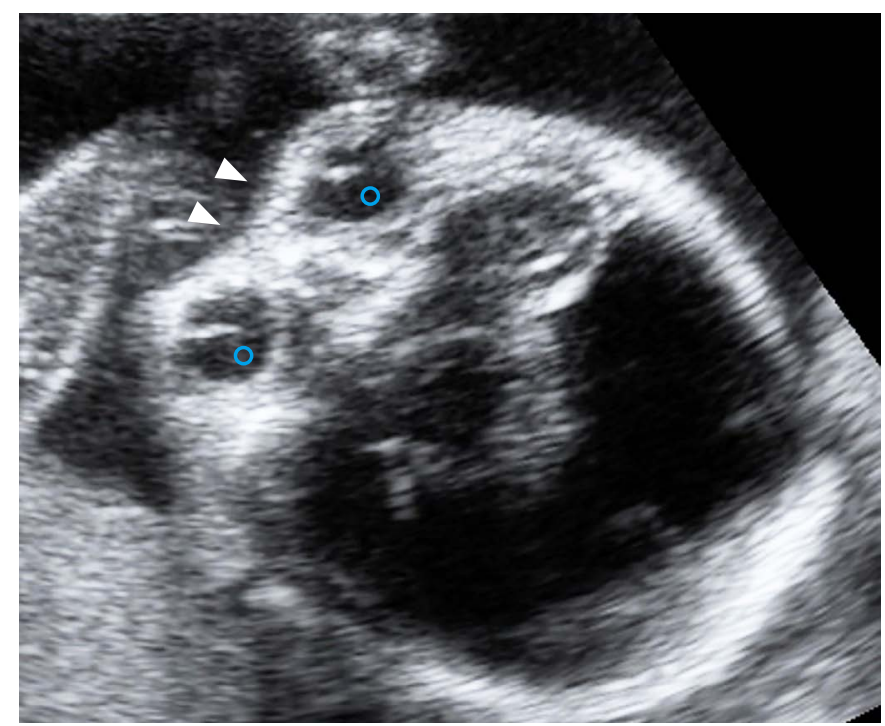

Fig. 12. A second-trimester fetus with hypotelorism. Axial view of the fetal face shows abnormally decreased distance (arrowheads) between the two orbits (circles).
(Figs. 15, 16), and craniosynostosis $[6,16,18,22]$. The images can be useful for counseling (Figs. 17, 18). Using 3D ultrasound (Figs. $19,20)$ can help differentiate closed from open sutures [22]. The use of $4 \mathrm{D}$ ultrasound can be used to assess facial expressions [23]. Although high-quality 3D rendered images of the fetal face are impressive to pregnant women, the use of $3 D$ ultrasound does not reduce maternal anxiety [24]. The effect of 3D/4D ultrasound on maternal-fetal bonding may be stronger than that of 2-dimensional ultrasound due to a higher level of visibility and recognition [25]. The resolution of $3 D$ ultrasound is limited when the fetus is leaning against the uterine wall or placenta or when the liquor is reduced.

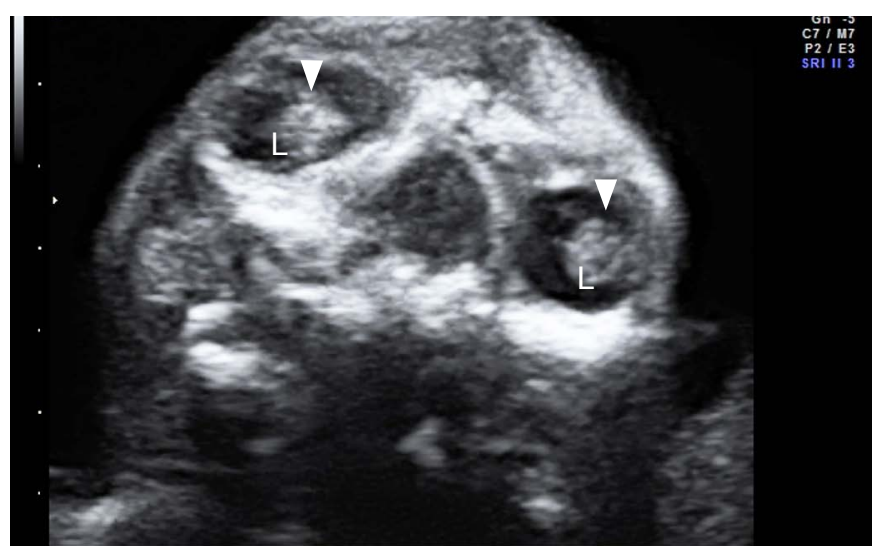

Fig. 13. A second-trimester fetus with bilateral cataracts. Axial view of the fetal face shows echogenicity (arrowheads) in the lens (L) of both eyes.

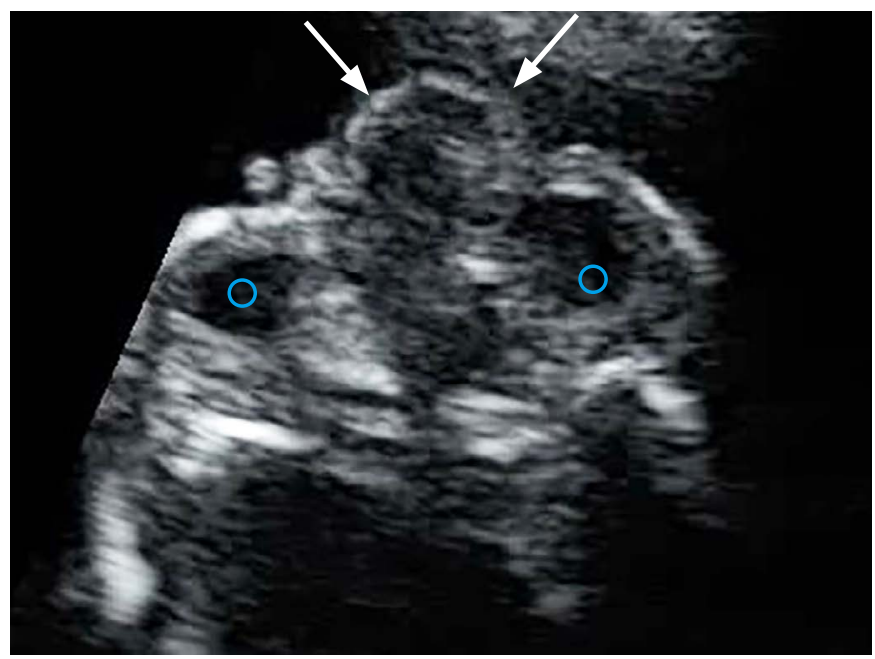

Fig. 14. A second-trimester fetus with a mass between the 2 orbits. Axial view of the fetal face shows a soft tissue mass (arrows) protruding between the two orbits (circles). 


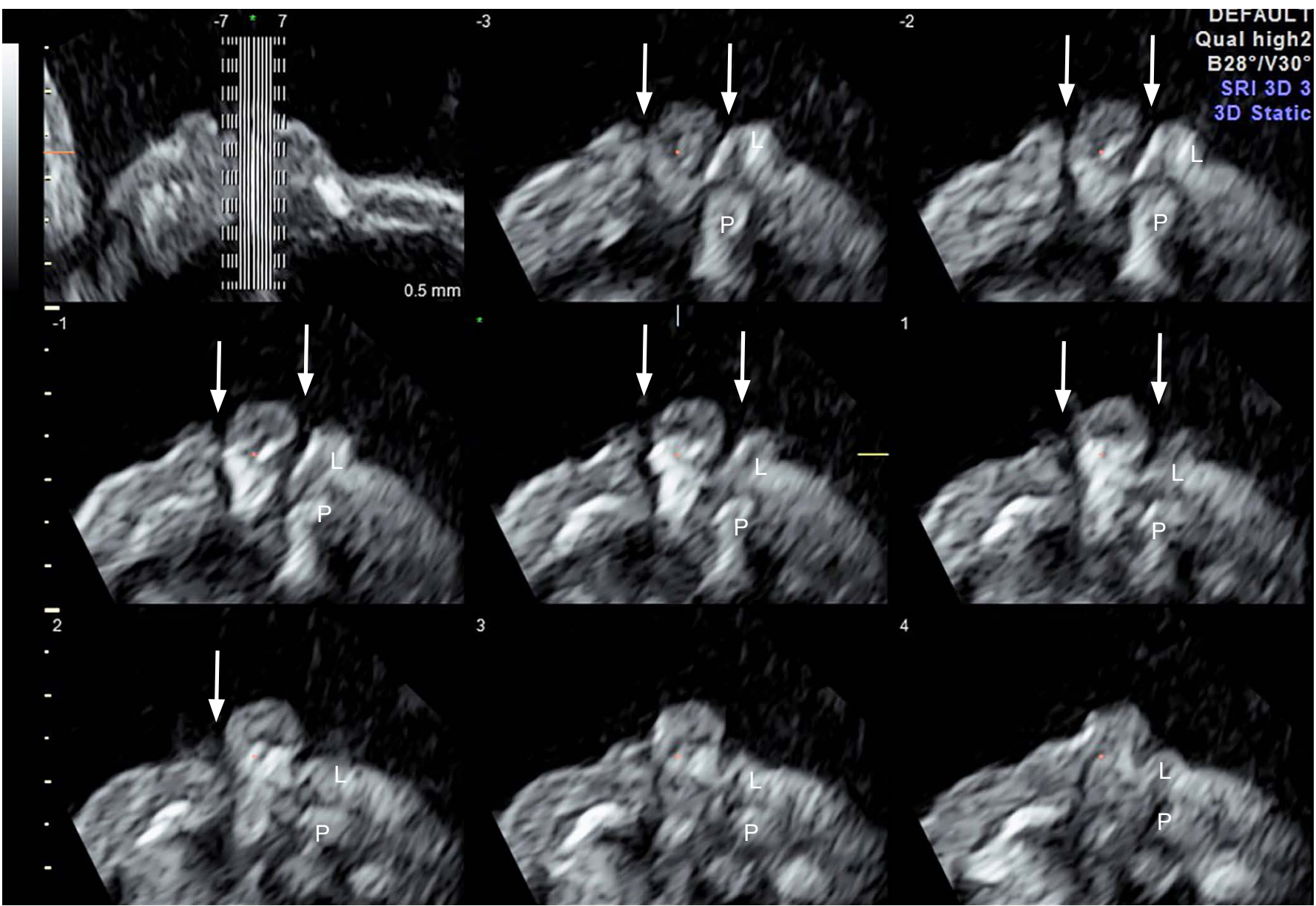

Fig. 15. A second-trimester fetus with bilateral cleft lip and palate. Three-dimensional multi-slice axial view of the fetal face shows a loss of integrity (arrows) of the lip (L) and palate (P) on both sides.

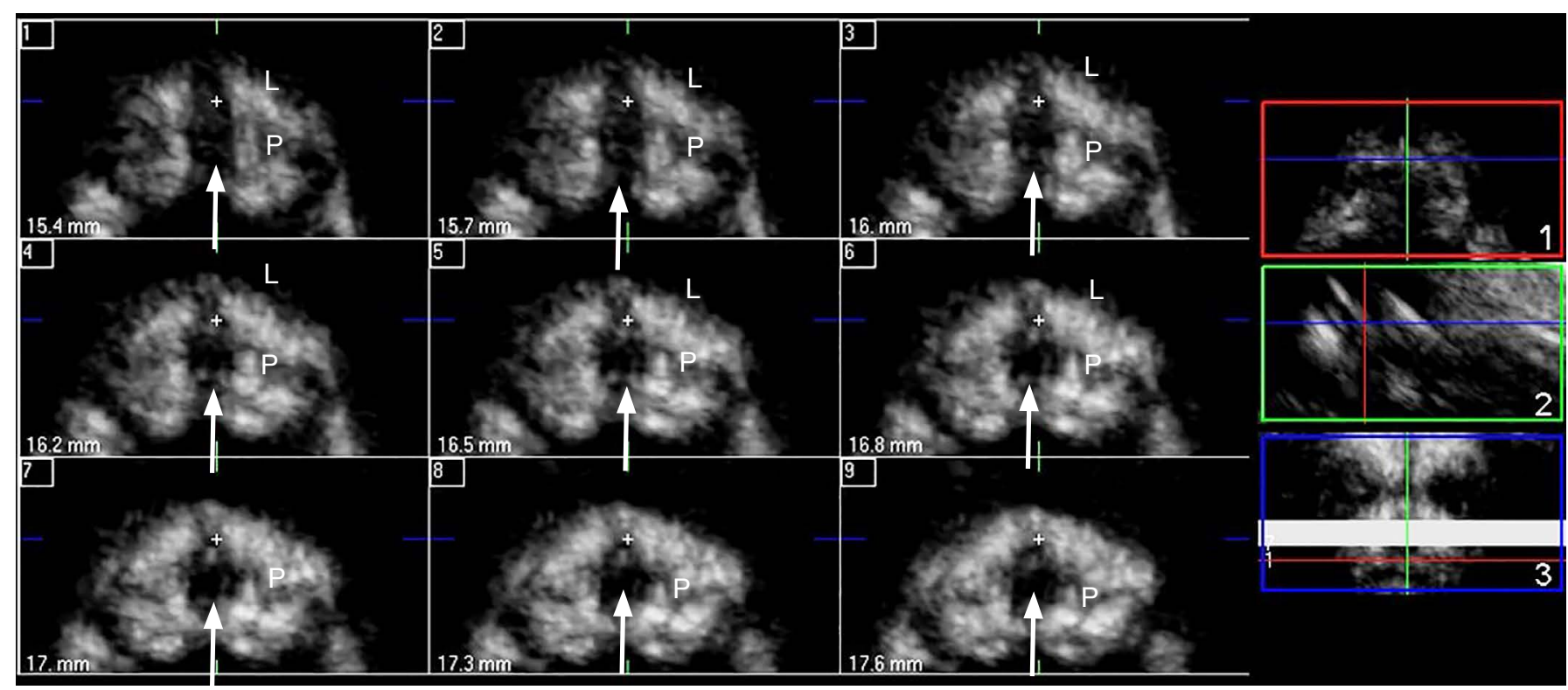

Fig. 16. A second-trimester fetus with midline cleft lip and palate. Three-dimensional multi-slice axial view of the fetal face shows a loss of integrity (arrows) of the lip (L) and palate (P) on the midline. Color boxes on the right side show the orientation of the active images on the left: axial view (1), sagittal view (2), and coronal view (3). 


\section{First-Trimester Sonography}

Between 11 and 13 weeks 6 days of gestation, the ISUOG guidelines suggest measuring the biparietal diameter and the head circumference, and assessing the integrity and echogenicity of the skull [12]. An attempt can be made to assess the orbits, interorbital distances, facial profile, ears, and the integrity of the mouth and lips [12]. A flat facial profile can be found in the first trimester (Fig. 21). However, some craniofacial abnormalities, such as craniosynostosis, cannot be diagnosed in the first trimester, and thus a secondtrimester anomaly scan remains the standard of care for fetal anatomical evaluation.

\section{Further Investigations}

Ultrasonographic images of some craniofacial abnormalities are illustrated (Figs. 1-19). When a cleft lip is found, it is essential to define whether it is unilateral, bilateral, or midline, and whether there is any cleft plate or amniotic band, because the prognosis and associated conditions vary accordingly [26]. Combined cleft lip and palate is more common that cleft lip alone [27], and the associated problems are more severe [26]. Unilateral/bilateral and median cleft lip are considered distinct conditions because their embryological origins are different [28]. Whereas the complete or partial lack of the fusion of the two lateral maxillary prominences with the medial nasal prominences on one or both sides results in

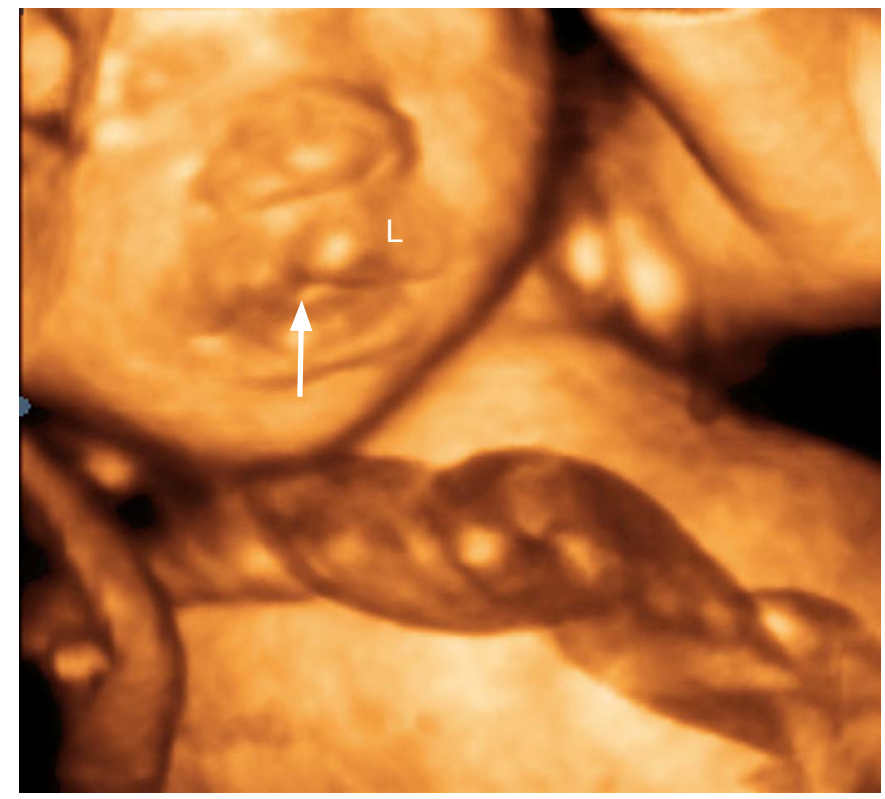

Fig. 17. A second-trimester fetus with unilateral cleft lip. Threedimensional surface-rendered image of the fetal face shows a cleft (arrow) on 1 side of the upper lip (L). unilateral or bilateral cleft lip, with or without cleft palate, median cleft lip is caused by the incomplete merging of the two medial nasal prominences [28]. Median cleft lip is particularly likely to be associated with other anomalies, chromosomal abnormalities, and poor outcomes $[26,29]$. Slash types of facial clefts caused by amniotic bands are usually severe [26].

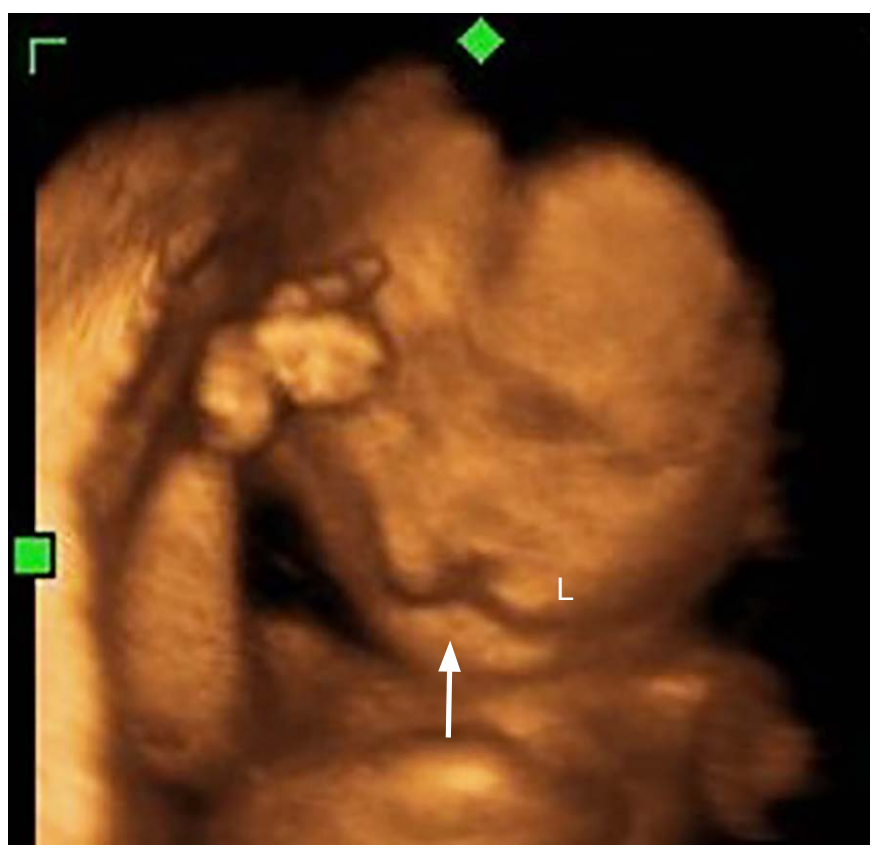

Fig. 18. A second-trimester fetus with midline cleft lip. Threedimensional surface-rendered image of the fetal face shows a cleft (arrow) on the midline of the upper lip (L).

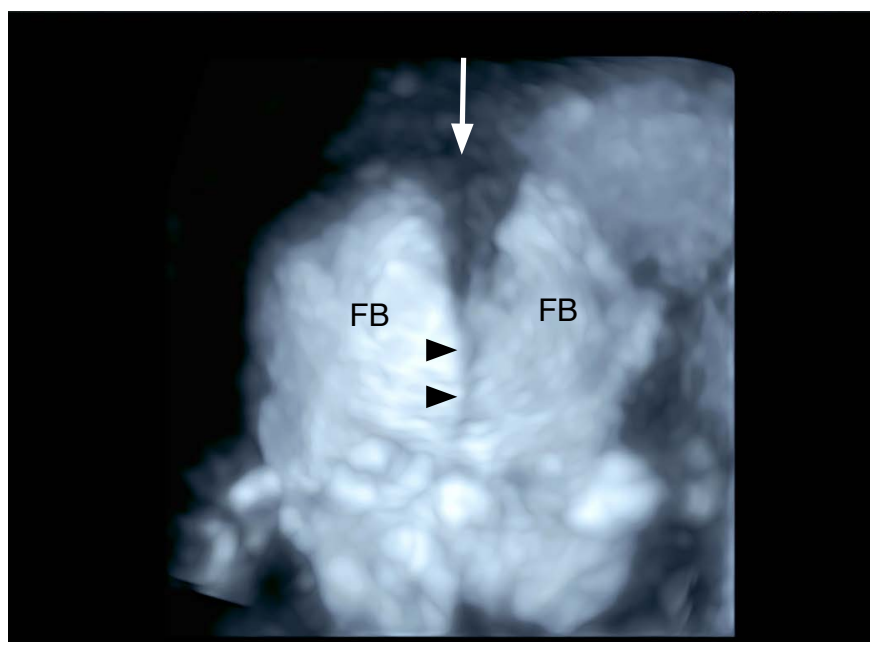

Fig. 19. A second-trimester fetus with a normal sagittal suture. Three-dimensional ultrasound surface-rendered image in skeletal mode of the frontal view of the fetal face shows a normal sagittal suture (arrowheads), anterior fontanelle (arrow), and frontal bones (FB). 


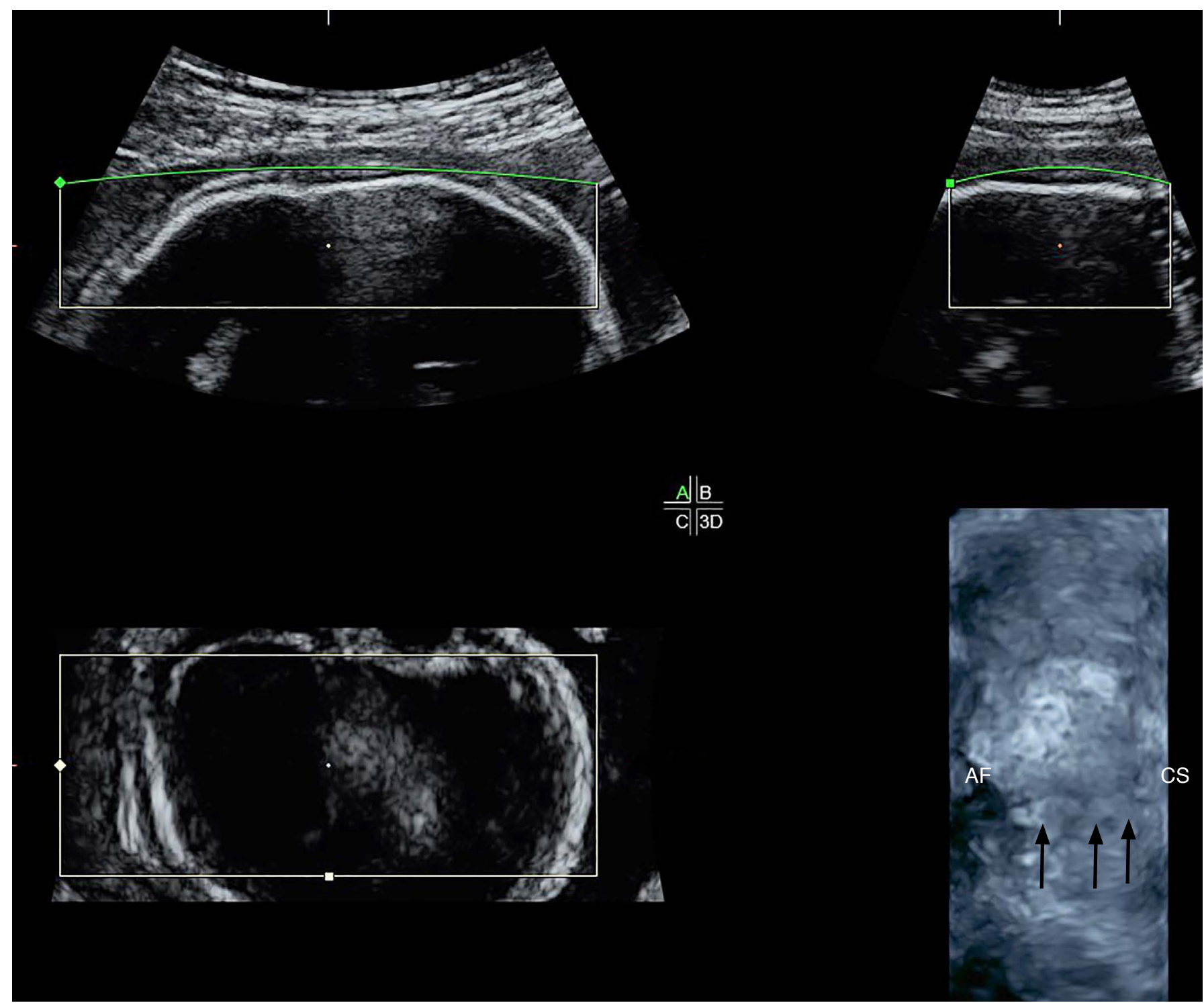

Fig. 20. A second-trimester fetus with craniosynostosis. Three-dimensional ultrasound surface-rendered image win skeletal mode of the axial view of the fetal skull shows narrowing (arrows) of the coronal suture (CS) and part of the anterior fontanelle (AF).

Whenever a craniofacial abnormality is found, it is important to perform a detailed scan to search for additional anomalies, especially other potentially subtle facial, central nervous system, heart, or extremity malformations. Many craniofacial abnormalities, including facial clefts, micrognathia, craniosynostosis, hypertelorism/ hypotelorism, microphthalmia/anophthalmia, cataracts, and anotia/microtia, are associated with a variety of syndromes and conditions (Table 4) $[8,16,26,29-33]$. In general, $10 \%$ of clefts were accompanied by a chromosomal abnormality and $27 \%$ had associated anomalies $[26,29,30]$. Roughly $15 \%$ of cases of craniosynostosis are syndromic $[8,16,33]$. Protrusion of the tongue can be a sign of Beckwith-Wiedemann syndrome or Down syndrome [30].

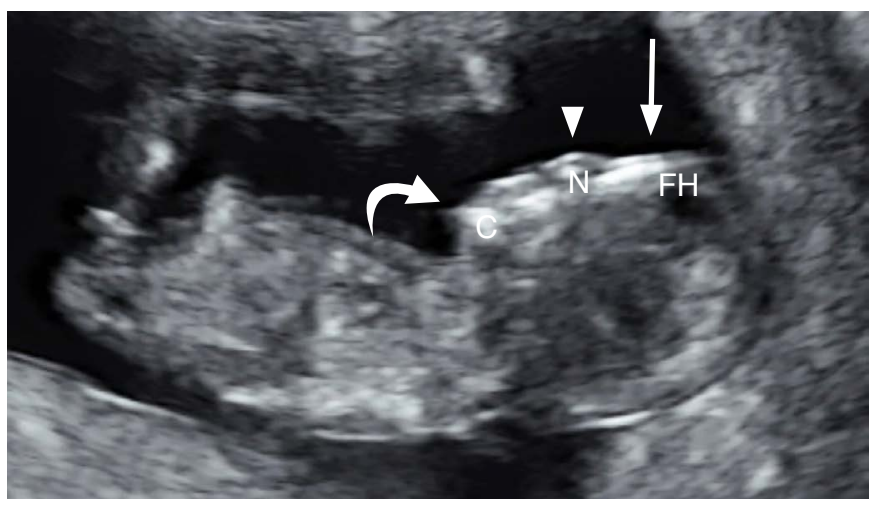

Fig. 21. A first-trimester fetus with a flat facial profile. Sagittal view of the fetal face shows a flat forehead (FH) (arrow), nose (N) (arrowhead), and a receding chin (C) (curved arrow). 
Table 4. Syndromes associated with craniofacial abnormalities

\begin{tabular}{|c|c|c|}
\hline & $\begin{array}{c}\text { Other } \\
\text { abnormalities }\end{array}$ & Syndromes \\
\hline Facial cleft & Hands & $\begin{array}{l}\text { Ectrodactyly, ectodermal dysplasia, } \\
\text { clefting (EEC) syndrome, oral-facial- } \\
\text { digital syndrome type I }\end{array}$ \\
\hline Facial cleft & Face and heart & $\begin{array}{l}\text { CHARGE (coloboma, heart anomaly, } \\
\text { choanal atresia, retardation, and } \\
\text { genital and ear anomalies) syndrome }\end{array}$ \\
\hline Micrognathia & Ear & Goldenhar syndrome \\
\hline Micrognathia & Limb & $\begin{array}{l}\text { Oral-mandibular-limb hypogenesis } \\
\text { syndrome, Nager syndrome, EEC } \\
\text { syndrome, Roberts syndrome }\end{array}$ \\
\hline Micrognathia & Face & $\begin{array}{l}\text { Pierre Robin sequence, Treacher } \\
\text { Collins syndrome }\end{array}$ \\
\hline Craniosynostosis & Face or limb & $\begin{array}{l}\text { Apert syndrome, Crouzon syndrome, } \\
\text { Carpenter syndrome, thanatophoric } \\
\text { dysplasia, Pfeiffer syndrome, Saethre- } \\
\text { Chotzen syndrome, Muenke } \\
\text { syndrome, Jackson-Weiss syndrome, } \\
\text { Antley-Bixtler syndrome, Wolf- } \\
\text { Hirschhorn (4p) syndrome }\end{array}$ \\
\hline
\end{tabular}

Fetal MRI can facilitate the evaluation of the palate, micrognathia, cranial sutures, brain, and other fetal structures [16,34]. If CHARGE (coloboma, heart anomaly, choanal atresia, retardation, and genital and ear anomalies) syndrome is suspected, fetal brain MRI can be helpful, but a normal result does not exclude the diagnosis [35].

When fetal cataract, microphthalmia or anophthalmia, or microcephaly is found, maternal blood can be taken to screen for congenital infections, including cytomegalovirus, rubella, toxoplasmosis, and varicella [36]. Zika virus is a possibility in at-risk areas [37].

As some disorders are familial, taking a family history is important. Inquiring about exposure to some medications, such as valproic acid, warfarin, or thalidomide, may reveal the cause of a flattened nose or facial cleft. Exposure to alcohol, drug use, or cigarette smoking are also relevant.

Invasive prenatal diagnostic techniques, including chorionic villus sampling or amniocentesis, can be considered for karyotyping, or preferably the use of a chromosomal microarray or fluorescence in situ hybridization, as appropriate. Many facial abnormalities, including median cleft lip, hypertelorism/hypotelorism, microphthalmia/anophthalmia, and cataract, are associated with chromosomal abnormalities, some of which are common and some of which are atypical. For example, hypertelorism is associated with deletion $4 p$ (Wolf-Hirschhorn syndrome) or tetrasomy 12p (PallisterKillian syndrome). The prenatal diagnosis of craniosynostosis depends on the ultrasonographic findings of craniofacial abnormalities and molecular analysis in some syndromes, such as Apert, Crouzon, Pfeiffer, and Jackson-Weiss syndromes, and SaethreChotzen syndrome when the family history is informative [3840]. FGFR2 mutations are associated with Apert syndrome. When CHARGE syndrome is strongly suspected, CHD7 molecular analysis can be considered to confirm the diagnosis [35]. Recently, noninvasive prenatal testing of microdeletions and microduplications by sequencing cell-free DNA in maternal blood has become feasible [41], but the sensitivity and false-positive rates need further investigation.

\section{Prognosis and Management}

The prognosis and management depend on the type and severity of craniofacial abnormalities, associated anomalies, and any underlying condition or chromosomal abnormality $[29,35]$. If the prognosis is poor, as in cases of multiple anomalies or associated aneuploidies, the option of termination of pregnancy can be offered depending on the gestational age and local regulations. Alternatively, continuation of pregnancy with prenatal counseling is appropriate for mild and isolated abnormalities such as cleft lip. Isolated macrocephaly (with a head circumference that is 2-3 standard deviations above the mean for gestational age), dolichocephaly, and brachycephaly are usually associated with normal outcomes [40,42]. Counseling of parents in suspected cases of craniosynostosis is not easy and should be commenced cautiously. Craniosynostosis is associated with a higher unplanned cesarean delivery rate, birth trauma, perinatal complications, and airway obstructions [43].

\section{Recurrence Risk}

The recurrence risk depends on the exact diagnosis. Isolated cleft lip/palate or cleft palate alone carry an increased recurrence risk. Most isolated cases of craniosynostosis have multifactorial or sporadic inheritance [8]. Common craniosynostosis syndromes such as Crouzon, Apert, and Pfeiffer syndromes are autosomal dominant disorders, but most are sporadic and result from de novo mutations. Pierre Robin syndrome is an autosomal recessive disorder.

\section{Conclusion}

The prenatal diagnosis of craniofacial abnormalities remains difficult, especially in the first trimester. A systematic approach to the fetal skull and face can increase the detection rate. When an abnormality is found, it is important to perform a detailed scan to determine its severity and to search for additional abnormalities. The use of 3D/4D ultrasound may be useful in the assessment of cleft palate and 
craniosynostosis. Fetal MRI facilitates the evaluation of the palate, micrognathia, cranial sutures, brain, and other fetal structures. Invasive prenatal diagnostic techniques are indicated to exclude chromosomal abnormalities. Molecular analysis in some syndromes is feasible when the family history is suggestive.

ORCID: Kwok Yin Leung: https://orcid.org/0000-0002-9289-6857

\section{Conflict of Interest}

No potential conflict of interest relevant to this article was reported.

\section{References}

1. Sohan K, Freer M, Mercer N, Soothill P, Kyle P. Prenatal detection of facial clefts. Fetal Diagn Ther 2001;16:196-199.

2. Moss A. Controversies in cleft lip and palate management. Ultrasound Obstet Gynecol 2001;18:420-421.

3. Cash C, Set P, Coleman N. The accuracy of antenatal ultrasound in the detection of facial clefts in a low-risk screening population. Ultrasound Obstet Gynecol 2001;18:432-436.

4. Sanders RC, Blackman LR, Hogge WA, Wulfsberg EA, Spevak PJ. Structural fetal abnormalities: the total picture. London: Mosby, 2002;33.

5. Pilu G, Reece EA, Romero R, Bovicelli L, Hobbins JC. Prenatal diagnosis of craniofacial malformations with ultrasonography. Am J Obstet Gynecol 1986;155:45-50.

6. Rotten D, Levaillant JM. Two- and three-dimensional sonographic assessment of the fetal face. 2. Analysis of cleft lip, alveolus and palate. Ultrasound Obstet Gynecol 2004;24:402-411.

7. Rubio El, Blask A, Bulas DI. Ultrasound and MR imaging findings in prenatal diagnosis of craniosynostosis syndromes. Pediatr Radiol 2016;46:709-718.

8. Delahaye S, Bernard JP, Renier D, Ville Y. Prenatal ultrasound diagnosis of fetal craniosynostosis. Ultrasound Obstet Gynecol 2003;21:347-353.

9. Salomon LJ, Alfirevic Z, Berghella V, Bilardo C, Hernandez-Andrade E, Johnsen $S L$, et al. Practice guidelines for performance of the routine mid-trimester fetal ultrasound scan. Ultrasound Obstet Gynecol 2011;37:116-126.

10. American Institute of Ultrasound in Medicine (AIUM) in conjunction with the American College of Radiology (ACR), the American College of Obstetricians and Gynecologists (ACOG), and the Society of Radiologists in Ultrasound (SRU). AIUM practice parameter for the performance of obstetric ultrasound examinations [Internet]. Laurel, MD: American Institute of Ultrasound in Medicine, 2013 [cited 2018 Jun 1]. Available from: http://www.aium.org/resources/ guidelines/obstetric.pdf.

11. Leung $K Y$, Poon $C F$, Teotico AR, Hata $T$, Won HS, Chen $M$, et al.
Recommendations on routine mid-trimester anomaly scan. J Obstet Gynaecol Res 2015;41:653-661.

12. Salomon LJ, Alfirevic Z, Bilardo CM, Chalouhi GE, Ghi T, Kagan KO, et al. ISUOG practice guidelines: performance of first-trimester fetal ultrasound scan. Ultrasound Obstet Gynecol 2013;41:102-113.

13. Tonni G, Panteghini M, Rossi A, Baldi M, Magnani C, Ferrari B, et al. Craniosynostosis: prenatal diagnosis by means of ultrasound and SSSE-MRI. Family series with report of neurodevelopmental outcome and review of the literature. Arch Gynecol Obstet 2011;283:909-916.

14. Roberto R, Pilu G, Jeanty P, Ghidini A, Hobbins JC. Prenatal diagnosis of congenital anomalies. Norwalk, CT: Appleton \& Lange, 1988.

15. Cornelissen MJ, Apon I, van der Meulen JJ, Groenenberg IA, Kraan-van der Est MN, Mathijssen IM, et al. Prenatal ultrasound parameters in single-suture craniosynostosis. J Matern Fetal Neonatal Med 2018;31:2050-2057.

16. Helfer TM, Peixoto AB, Tonni G, Araujo Junior E. Craniosynostosis: prenatal diagnosis by 2D/3D ultrasound, magnetic resonance imaging and computed tomography. Med Ultrason 2016;18:378385.

17. Leibovitz Z, Daniel-Spiegel E, Malinger G, Haratz K, Tamarkin M, Gindes $L$, et al. Prediction of microcephaly at birth using three reference ranges for fetal head circumference: can we improve prenatal diagnosis? Ultrasound Obstet Gynecol 2016;47:586-592.

18. Rotten $\mathrm{D}$, Levaillant JM. Two- and three-dimensional sonographic assessment of the fetal face. 1. A systematic analysis of the normal face. Ultrasound Obstet Gynecol 2004;23:224-231.

19. Maarse W, Pistorius LR, Van Eeten WK, Breugem CC, Kon M, Van den Boogaard MJ, et al. Prenatal ultrasound screening for orofacial clefts. Ultrasound Obstet Gynecol 2011;38:434-439.

20. Wilhelm L, Borgers $H$. The 'equals sign': a novel marker in the diagnosis of fetal isolated cleft palate. Ultrasound Obstet Gynecol 2010:36:439-444.

21. Rotten $D$, Levaillant JM, Martinez $H$, Ducou le Pointe $H$, Vicaut E. The fetal mandible: a 2D and 3D sonographic approach to the diagnosis of retrognathia and micrognathia. Ultrasound Obstet Gynecol 2002;19:122-130.

22. Faro C, Chaoui R, Wegrzyn P, Levaillant JM, Benoit B, Nicolaides KH. Metopic suture in fetuses with Apert syndrome at 22-27 weeks of gestation. Ultrasound Obstet Gynecol 2006;27:28-33.

23. AboEllail MA, Kanenishi K, Mori N, Mohamed OA, Hata T. 4D ultrasound study of fetal facial expressions in the third trimester of pregnancy. J Matern Fetal Neonatal Med 2018;31:1856-1864.

24. Leung KY, Ngai CS, Lee A, Chan HY, Leung WC, Lee CP, et al. The effects on maternal anxiety of two-dimensional versus two- plus three-/four-dimensional ultrasound in pregnancies at risk of fetal abnormalities: A randomized study. Ultrasound Obstet Gynecol 2006:28:249-254. 
25. de Jong-Pleij EA, Ribbert LS, Pistorius LR, Tromp E, Mulder EJ, Bilardo CM. Three-dimensional ultrasound and maternal bonding, a third trimester study and a review. Prenat Diagn 2013;33:81-88.

26. Nyberg DA, Sickler GK, Hegge FN, Kramer DJ, Kropp RJ. Fetal cleft lip with and without cleft palate: US classification and correlation with outcome. Radiology 1995;195:677-684.

27. Yang Y, Liu H, Ma R, Jin L. Prevalence of cleft lip/palate in the Fangshan District of Beijing, 2006-2012. Cleft Palate Craniofac J 2018;55:1296-1301.

28. Kernahan DA. The striped Y: a symbolic classification for cleft lip and palate. Plast Reconstr Surg 1971;47:469-470.

29. Berge SJ, Plath H, Van de Vondel PT, Appel T, Niederhagen B, Von Lindern JJ, et al. Fetal cleft lip and palate: sonographic diagnosis, chromosomal abnormalities, associated anomalies and postnatal outcome in 70 fetuses. Ultrasound Obstet Gynecol 2001;18:422431.

30. Nicolaides KH, Salvesen DR, Snijders RJ, Gosden CM. Fetal facial defects: associated malformations and chromosomal abnormalities. Fetal Diagn Ther 1993;8:1-9.

31. Stoll C, Alembik Y, Dott B, Roth MP. Associated anomalies in cases with anotia and microtia. Eur J Med Genet 2016;59:607-614.

32. Ashwal E, Achiron A, Gilboa Y, Berkenstadt M, Rosner M, Achiron R. Prenatal ultrasonographic diagnosis of cataract: in utero manifestations of cryptic sisease. Ultraschall Med 2018;39:213218.

33. Keating RF. Craniosynostosis: diagnosis and management in the new millennium. Pediatr Ann 1997;26:600-612.

34. Resnick CM, Kooiman TD, Calabrese CE, Zurakowski D, Padwa BL, Koudstaal MJ, et al. An algorithm for predicting Robin sequence from fetal MRI. Prenat Diagn 2018;38:357-364.
35. Busa T, Legendre M, Bauge M, Quarello E, Bretelle F, Bilan F, et al. Prenatal findings in children with early postnatal diagnosis of CHARGE syndrome. Prenat Diagn 2016;36:561-567.

36. O'Neill JF. The ocular manifestations of congenital infection: a study of the early effect and long-term outcome of maternally transmitted rubella and toxoplasmosis. Trans Am Ophthalmol Soc 1998;96:813879.

37. Sanz Cortes M, Rivera AM, Yepez M, Guimaraes CV, Diaz Yunes I, Zarutskie $A$, et al. Clinical assessment and brain findings in a cohort of mothers, fetuses and infants infected with ZIKA virus. Am J Obstet Gynecol 2018;218:440.e1-440.e36.

38. Ferreira JC, Carter SM, Bernstein PS, Jabs EW, Glickstein JS, Marion RW, et al. Second-trimester molecular prenatal diagnosis of sporadic Apert syndrome following suspicious ultrasound findings. Ultrasound Obstet Gynecol 1999;14:426-430.

39. Schwartz M, Kreiborg S, Skovby F. First-trimester prenatal diagnosis of Crouzon syndrome. Prenat Diagn 1996;16:155-158.

40. el Ghouzzi V, Le Merrer M, Perrin-Schmitt F, Lajeunie E, Benit $P$, Renier $D$, et al. Mutations of the TWIST gene in the SaethreChotzen syndrome. Nat Genet 1997;15:42-46.

41. Zhao C, Tynan J, Ehrich M, Hannum G, McCullough R, Saldivar JS, et al. Detection of fetal subchromosomal abnormalities by sequencing circulating cell-free DNA from maternal plasma. Clin Chem 2015;61:608-616.

42. Biran-Gol Y, Malinger G, Cohen H, Davidovitch M, Lev D, Lerman-Sagie $T$, et al. Developmental outcome of isolated fetal macrocephaly. Ultrasound Obstet Gynecol 2010;36:147-153.

43. Miller C, Losken HW, Towbin R, Bowen A, Mooney MP, Towbin A, et al. Ultrasound diagnosis of craniosynostosis. Cleft Palate Craniofac J 2002;39:73-80. 